\title{
UMA FLOR NO DESERTO: A PRIMAVERA ÁRABE NO EGITO (2011-2012)
}

\author{
Juan Alexis Acevedo Navarrete
}

Resumo: Egito durante o ano de 2011 viu-se sacudido por uma onda de protestos que derrocaram a um regime de 30 anos. O presente trabalho tem por objetivo analisar este problema histórico, compreender as principais causas, assinalar alguns fatos cruciais do desenvolvimento dos protestos e finalmente refletir sobre a situação atual do país africano. A convergência de diversos fatores desencadeou um processo revolucionário, tais como a situação econômica, a corrupção, a tecnologia e o governo autoritário de Hosni Mubarak. Isto se corrobora mediante o estudo de diversos historiadores, o uso de índices internacionais, e artigos de imprensa árabe e internacional.

Palavras chaves: primavera árabe - Juventude egípcia - protestos - Regime autoritário.

Resumen: Egipto durante el año de 2011 se ha visto sacudido por una oleada de protestas que derrocaron a un régimen de 30 años. El presente trabajo tiene por objetivo analizar este problema histórico, dilucidar las principales causas, señalar algunos hechos cruciales del desarrollo de las protestas y finalmente reflexionar sobre la situación actual del país africano. La convergencia de diversos factores desencadenaron un proceso revolucionario, tales como la situación económica, la corrupción, la tecnología y el gobierno autoritario de Hosni Mubarak. Esto se corrobora mediante el estudio de diversos historiadores, el uso de índices internacionales, y artículos de prensa árabe e internacional.

Palabras Claves: primavera árabe - Juventud egipcia - protestas - Régimen autoritario.

${ }^{1}$ Universidade De Playa Ancha, Facultade De Humanidades, Departamento Do Historia, Pedagogía En Historia E Geografía. Valparaíso, Chile 


\section{Introdução}

"La juventud árabe ha demostrado tener unas esperanzas e ideales que no difieren de las de otros jóvenes que contribuyeron a la transición democrática en Europa Oriental, América Latina y Asia”. (Rashid Khalidi).

Egito durante ano de 2011 viu-se sacudido por uma onda de protestos que derrocaram a um regime há mais de 30 anos. O presente trabalho tem por objetivo analisar este evento, compreender as principais causas, apontar para alguns fatos cruciais do desenvolvimento dos protestos e finalmente refletir sobre a situação atual do país africano. A hipótese da investigação diz relação com o caráter das causas, pois a convergência de fatores, como a população jovem, os meios tecnológicos, as repressões de um governo impopular e autoritário, a corrupção, e os problemas econômicos, sobretudo o desemprego nas camadas jovens da sociedade, serão em soma os detonantes das revoltas no país do norte de África.

Para dar sustento a nosso estudo, utilizaram-se diversos artigos de historiadores, como também artigos de imprensa escrita, tanto de meios egípcios como internacionais. O desenvolvimento da questão começa com uma análise do contexto histórico do Egito, no qual se propõem alguns antecedentes relevantes para compreender o presente. 
Revista Vernáculo, $n^{o} 30,2^{\circ}$ sem/2012

Posteriormente, analisam-se as causas antes descritas, as quais são cotejadas com outras percepções da problemática, como é a postura de Andrey V. Korotayev ${ }^{2}$. Os acontecimentos do dia 25 de Janeiro de 2011 foram o começo dos protestos que finalizaram com a queda de Hosni Mubarak no dia 11 de Fevereiro de 2011. Comparam-se artigos de jornais, entre diários a favor do regime e outros meios privados, os quais mostram um discurso diferenciado dos acontecimentos.

\section{Desenvolvimento}

"No tememos que nos maten, nos hieran, nos detengan o nos torturen. Ya no hay miedo. La gente quiere vivir con dignidad. Así que no vamos a parar”3.

A Primavera Árabe, como conceito alude às diversas manifestações sociais ocorridas a começos do ano 2011, desencadeando uma crise política em diversos estados da órbita árabe, fundamentalmente ao norte de África.

\footnotetext{
${ }^{2}$ Andrey V. Korotayev é um antropólogo, economista, historiador, e sociólogo Russo. Dentro de suas principais obras relacionam-se com a teoria do sistema mundial e as dinâmicas sociais e econômicas.

${ }^{3}$ Extrato de depoimento. Ahmed Harara, dentista que resultou ferido em um olho por impactos de perdigones durante as manifestações de Egito o 28 de janeiro de 2011 e depois no outro, o 19 de novembro de 2011, pelo que ficou cego. Fonte: Relatório 2012 anistia internacional. $\mathrm{O}$ estado dos direitos Humanos no mundo.
} 
A análise historiográfica mostra o conceito, por meios de diversos acontecimentos, de tal modo que em 1848 aconteceu a "Primavera dos Povos":

En la historia del mundo moderno se han dado muchas revoluciones mayores, y desde luego buen número de ellas con mucho más éxito. Sin embargo, ninguna se extendió con tanta rapidez y amplitud, pues ésta se propagó como un incendio a través de fronteras, países e incluso océanos ${ }^{4}$

Por outro lado, vemos que os processos democráticos que ocorreram em diversas partes do mundo, não incidiram no mundo árabe. Seria esse um ponto importante dos levantes populares na Tunísia e posteriormente no Egito, exigia-se: maiores liberdades e reformas políticas nos sistemas de governos de características autoritárias. Bárbara Azaola Piazza já no ano 20055 , distinguiu que os diversos atores políticos assinalavam que a situação egípcia estava colapsada pela falta de liberdade e pelo autoritarismo. Em consequência de tal situação, deu-se a circulação de um discurso que sintetizava a

\footnotetext{
${ }^{4}$ HOBSBAWM, Eric. La era del capital 1848-1875, Editorial crítica, 2007, pág. 22. ${ }^{5}$ Licenciada em Filosofia e Letras, especialidade: Filología Árabe e Islã. Departamento de Estudos Árabes e Islâmicos da Faculdade de Filosofia e Letras da Universidade Autônoma de Madri.
} 
situação: o "Kifaya", que em português quer dizer "Basta", ou "Ao sha'b yurid isqat ao nizam." ("O povo quer que caia o regime.")

Eric Hobsbawm em sua entrevista à $\mathrm{BBC}$ realizada a fins de 2011 assinalou o seguinte:

Me recuerda a 1848, otra revolución autoimpulsada que comenzó en un solo país y después se extendió por todo el continente en poco tiempo... Lo que los une es un descontento común y unas fuerzas de movilización comunes: una clase media modernizadora, más que todo joven, estudiantes y, sobre todo, una tecnología que hace que hoy sea mucho más fácil movilizar protestas ${ }^{6}$

Para compreender parte da história do Egito, e o contexto no qual se desenvolveram os protestos da Primavera Árabe, é relevante analisar os enunciados propostos por José Luis das Heras García. Devemos ir a 1882, momento no qual Egito passou a ser uma colônia britânica, o que durou até 1923, momento onde se estabeleceu uma "independência vigiada". A independência de fato só viria em 19 de Outubro de 1954. Depois da experiência colonial, abriu-se um processo revolucionário que desacreditou ao Rei Faruq, dando origem ao

\footnotetext{
${ }^{6}$ Entrevista de BBC Mundo, "Eric Hobsbawm: 2011 "me recuerda a 1848". ([em linha]

Disponível

em: http://www.bbc.co.uk/mundo/noticias/2011/12/111229_primavera_arabe_hobsbawn_r evolucion_pea.shtml?print=1 [2013, Setembro])
} 
governo de Gamal Abdel Nasser durante a década de 1950. Posteriormente, Egito terá grande relevância no mundo, sobretudo em um contexto de guerra fria, alinhado no bloco da União Soviética até a morte de Nasser em 1970. O período seguinte esteve a cargo de Anuar o-Sadat, quem deu um giro na relação com a URSS e passou a estreitar as relações com Estados Unidos. No começo da década de 1980 o líder foi assassinado, deixando no poder a Hosni Mubarak. Este último governou o Egito por quase 30 anos:

Obsesionado, como se ha subrayado, por la seguridad y la estabilidad. La ley de Emergencia, decretada tras el asesinato de Sadat, le ha convertido en un dictador de facto (que ha sufrido diversos atentados resultando, en ocasiones, herido leve) aunque su alianza con EE.UU y el turismo le hayan permitido mantener una fachada de aceptabilidad bajo la etiqueta de "líder moderado"; con el tiempo, como hemos tenido ocasión de leer, el humor egipcio ha trocado su título de "Rais" (presidente) por el de Faraón. ${ }^{7}$

Dito isto, é apropriado observar alguns antecedentes das convulsões egípcias de 2011, sobretudo no marco das liberdades políticas e individuais do povo. Nader Fergancy assinala que para o 2005, se levantaram diversos movimentos que exigiam reformas

${ }^{7}$ DE LAS HERAS, José Luis, Egipto: democracia de papel, 2011 pág. 5. 
radicais ao governo de Mubarak, sendo um precedente para o que ocorreria 6 anos mais tarde. Em definitivo, as aspirações populares recusavam o "prolongamento" do presidente para um quinto período (cada mandato presidencial era seis anos) e não aceitavam uma eventual sucessão de cunho. Para isso, os cidadãos puxaram por uma emenda constitucional que promovesse a concorrência pela administração do Estado, entre diversos candidatos e que deviam ser eleitos por uma votação direta, somado a uma fiscalização de tribunais. Pedia-se que o presidente não pudesse ser reeleito mais de duas vezes consecutivas. A resposta do governo egípcio foi favorável às reformas políticas.

Sin embargo, existen pruebas fehacientes de que su intención de compromiso con la reforma no es del todo sincera, o eso parece, ya que la conducta real de la autoridad gobernante no se corresponde con dichas intenciones. Ejemplos de esta conducta incluyen la introducción de iniciativas de reforma que se limitan a recorrer la mínima distancia posible en la preparación de una agenda reformista que constituiría un cambio serio hacia una sociedad de libertad y buen gobierno... Mientras tanto, las autoridades de los Estados que afirman estar implementando la reforma siguen cometiendo violaciones flagrantes de los derechos de aquellos que la reclaman. De hecho, la afirmación de estar implementando la reforma no parece ser nada más que un 
velo con el que disimular la perpetuación de las actuales estructuras de opresión. ${ }^{8}$

A situação era de uma bomba relógio, um processo que estouraria à medida que as partes e as engrenagens da história fossem se conjugando, é um momento em que a história se acelera e desencadeia diversas mudanças nas estruturas que tinham estado quietas por mais de 30 anos.

O fenômeno possui uma explicação múltipla, sendo a história egípcia um deles. São variados os fatores que nos ajudam a compreender a queda de um regime despótico, em matéria de semanas, tais como, a situação econômica, a demografia, o autoritarismo político, a corrupção, as condições sociais adversas e a confiança de uma nova geração de jovens. A isso, se lhe deve agregar, os meios de comunicação que têm jogado um papel transcendente, tal como o tem enunciado Eric Hobsbawm e Rashid Khalidi, as redes sociais têm facilitado a organização e têm posto a Egito na maioria dos titulares e artigos de imprensa internacional. Assim mesmo, a situação em Tunísia, permitiu a emanação do movimento para Egito durante o mês de Janeiro em 2011.

\footnotetext{
${ }^{8}$ FERGANY, Nader, La "primavera de la reforma árabe” aún debe florecer, Med2006, editores IEMed, pág. 65.
} 
Rashid Khalidi, em seu artigo "Las revoluciones tunecina y egipcia", ilustra os acontecimentos, assinalando a importância da revolução, pois o cataloga como um "momento histórico". Somado a isso, realça a atitude da juventude árabe acuñando o seguinte:

La juventud árabe muestra tener unas esperanzas y unos ideales que no difieren de los albergados por los jóvenes que contribuyeron a las transiciones democráticas de Europa Oriental, América Latina y Asia meridional, sudoriental y oriental ${ }^{9}$.

Sem dúvida, a juventude egípcia, cansada dos abusos, a corrupção e o desprezo dos governantes para com o povo, pode ter feito este levantamento. Nas palavras do autor:

han desatado la energía, el dinamismo y la inteligencia de la joven generación del mundo árabe, contenida hasta ese momento por un sistema que la trató con desprecio y que concentró principalmente el poder en manos de una generación mucho mayor ${ }^{10}$.

\footnotetext{
${ }^{9}$ KHALID, Rashid, Las revoluciones tunecina y egipcia, Revista Vanguardia Dossier no 39, Abril-Junio 2011. Pág. 17

${ }^{10}$ KHALIDI, Rashid, Las revoluciones tunecina y egipcia, Revista Vanguardia Dossier nº 39, Abril-Junio 2011. Pág. 18
} 
Os jovens seriam os atores principais, pois conquistaram uma confiança e uma segurança que tem traspassado as fronteiras de seu país. Esta troca gerações da população permite uma onda de ideias e vontades, já que a maioria dos atores, tinham menos de 30 anos, em consequência, tinham vivido sob um regime autoritário e não conheceram uma época em que o governo não estivesse em mãos de oficiais militares ou soberanos absolutos.

Por exemplo, para Khalidi, Rashid uma das causas diretas da primavera árabe egípcia, foi atitude do governo, pois:

Uno de los peores rasgos de ese mosaico de regímenes autoritarios fue el desprecio de los gobernantes hacia sus pueblos. El pueblo, según sostenían esos dirigentes, era demasiado inmaduro para tomar decisiones, elegir a sus representantes o distribuir excedentes sociales o ayuda extranjera. Todo eso y muchas otras cosas eran realizadas en su nombre por quienes eran mejores que ellos, sus gobernantes. Todo aquel que desafiara los límites trazados por quienes detentaban el poder, ya fuera el jefe de Estado o el policía de la calle, se arriesgaba a ser objeto de una brutalidad desenfrenada. ${ }^{11}$

O ambiente não era propício para protestos de nenhum tipo, algo demonstrado, depois da morte de um jovem chamado Jalid Said, quem

\footnotetext{
${ }^{11}$ KHALIDI, Rashid, Las revoluciones tunecina y egipcia, Revista Vanguardia Dossier nº 39, Abril-Junio 2011. Pág. 19
} 
havia gravado, em Alexandria, a corrupção policial em junho de 2010. A consequência de seu ato foi a pena máxima, já que os oficiais ao surpreendê-lo, deram-lhe morte mediante golpes a plena luz do dia. Esta constante de violações à dignidade dos cidadãos teria sido uma das causas das revoltas.

O contexto de Tunis, também influiu nas revoltas egípcias, já que outro jovem (Mohamed Buazizi) reagiu e se imolou em frente à sociedade, inspirando a organização desta e a difusão dos ideais ao resto das nações árabes, em especial a Egito.

Os meios de comunicação como a imprensa, também tentaram explicar a caótica situação em Egito. Causas de ordem econômica e social, como a pobreza, a alta nos preços de alimentos, entre outras coisas. Meios como o "Ao Arabiya News", dispôs o seguinte em sua edição da terça-feira 25 de janeiro de 2011: "Milhares de manifestantes saem às ruas em Egito". Dentro do desenvolvimento da notícia, advertese: "Los crecientes precios de los alimentos, la pobreza, el desempleo y el autoritarismo que sofoca las protestas públicas de forma rápida y brutalmente a menudo". 12

A explicação é similar noutro médio, a BBC. Ao assinalar que Egito é:

\footnotetext{
${ }^{12}$ Diario Al Arabiya News, 25 de Janeiro 2011. ([em linha] Disponível em:http://www.alarabiya.net/articles/2011/01/25/134920.html. [2013, Setembro])
} 
un país que tiene muchos de los mismos problemas sociales y políticos que provocaron disturbios en Túnez el aumento de precio de los alimentos, el alto desempleo y el enojo ante la corrupción oficial...Hay frustraciones profundas en la sociedad egipcia...los egipcios están casi tan desilusionados con la oposición como lo están con el gobierno. ${ }^{13}$

Para outros autores, as causas são notadamente de ordem econômica, tais como Juan Moscoso, em seu artigo "Ante a primavera árabe", no qual assinala que os cidadãos egípcios "perderam o medo a se manifestar". Somado a isso, fala das necessárias reformas políticas e econômicas, em onde diz: "no hay que olvidar que algunas de las principales protestas tuvieron un origen económico". ${ }^{14}$

Conquanto, até aqui parecem claras estas causas, devem ser contrastado com outras perspectivas. A análise, que precisamos é feita pelo historiador Andrey V. Korotayev, que sustenta que os jornais, ao tratar o conflito egípcio, não têm sido cautelosos quanto as suas causas, sobretudo nas de ordem econômico. É por isso, que falam que Egito, durante a época de Mubarak, experimentava um crescimento econômico sustentado (tal como se aprecia no gráfico 1), e não um estancamento

\footnotetext{
${ }^{13}$ Notica BBC Mundo, 25 de enero de 2011. ([em linha] Disponível em: http://www.bbc.co.uk/mundo/noticias/2011/01/110125_egipto_cairo_revueltas_jrg.sht ml. [2013, Septiembre])

${ }^{14}$ MOSCOSO, Juan, Ante la primavera árabe, Revista Escritura pública no 69, 2011. Pág. 45
} 
econômico. Os julgamentos do autor: "Evidently, during Mubarak's reign (1981-2011) the Egyptian economy was developing rather dynamically". ${ }^{15}$

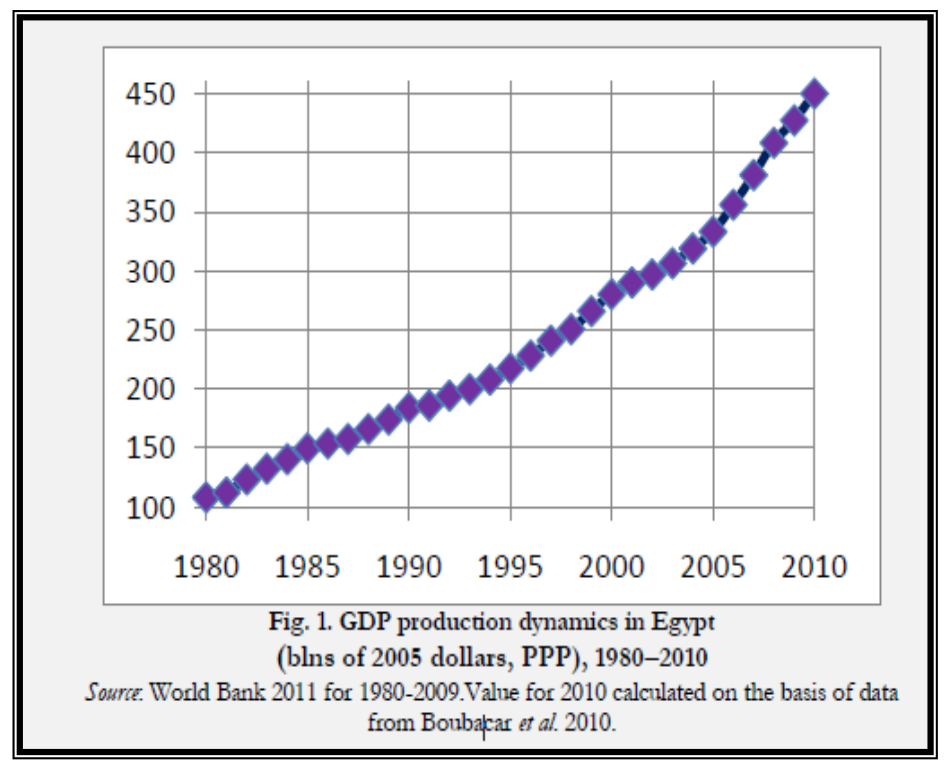

Grafico 1. Fuente: Egyptian Revolution: A Demographic Structural Analiysis

Assim mesmo, Korotayev, assinala que o desemprego em Egito, não era extremo nos meses dantes da revolução, senão que mais bem se mantinha controlado, e inclusive estava por embaixo de taxas de

${ }^{15}$ KOROTAYEV Andrey, Egyptian revolution: a Demographic Structural Analysis, Revista Entelequia, sección Mundo contemporáneo. Primavera 2011. 
desemprego de países como Portugal, Colômbia ou inclusive França, entre outros casos. (Veja-se gráfico 2)

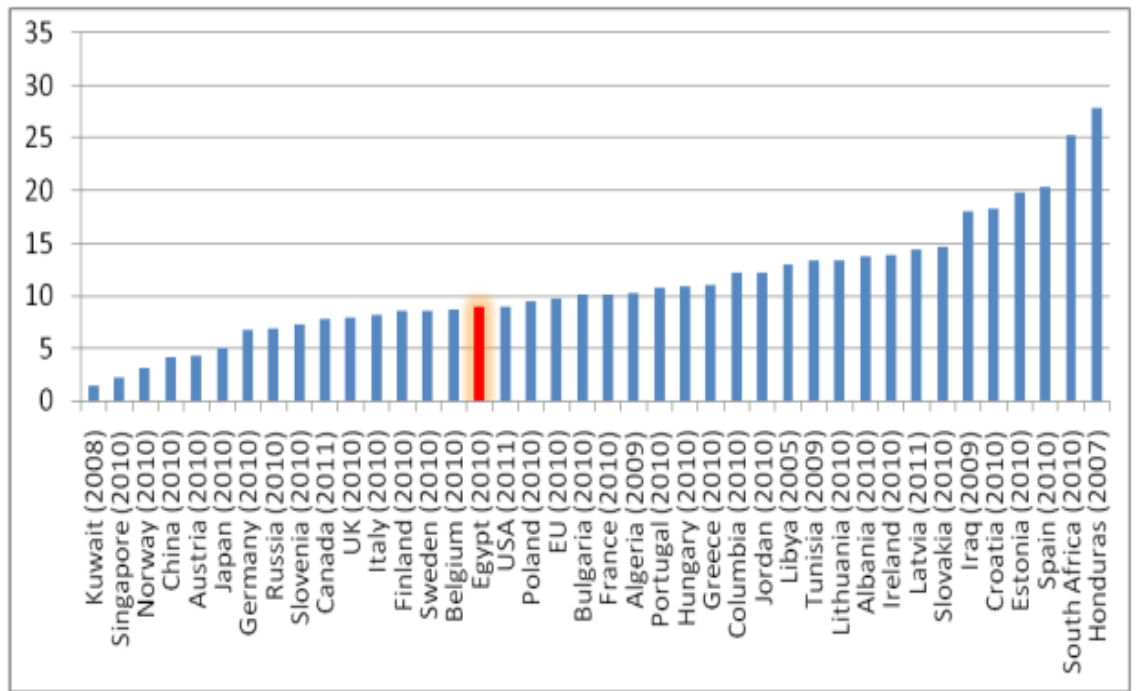

Fig. 7. Unemployment level in some countries, $\%, \mathbf{2 0 1 0}^{12}$

Gráfico 2. Fuente: Egyptian Revolution: A Demographic Structural Analiysis.

O problema a seu ver estaria arraigado noutras causas, sobretudo no desemprego, nas camadas jovens da sociedade. Os quais como se assinalou foram os principais atores dos protestos. Contudo, é necessário avaliar as causas da Primavera Árabe em Egito, é por isso que devemos analisar, por exemplo, o caso da corrupção.

A corrupção segundo o Índice de Percepção da Corrupção 2010, Egito, encontra-se com um índice de 3.1, dentro de uma escala de 0 a 
10 , onde 0 significa um país altamente corrupto, enquanto 10 , quer dizer uma zona com pouca corrupção. É preciso enunciar, que o México possui o mesmo resultado, e que o Egito se encontrava no nível de países como Argentina, Venezuela, Paraguai, Rússia, entre outros. Isso obriga-nos a perguntar, se a corrupção é a causa principal dos distúrbios. A resposta é negativa, pois a convergência de diversos fatores são os detonantes. Países piores que Egito, no que diz respeito à corrupção, não se encaminharam para processos revolucionários. Em uma análise, comparado com o ano de 2011, adverte-se que Egito teve aumento seus níveis de corrupção, baixando de 3.1 a 2.9, o qual nos abre a outras possibilidades de estudo que veremos mais adiante na situação atual de Egito.

Existem ademais propostas que reconhecem a existência das mesmas causas que provocaram os protestos árabes, noutros países, mas que não têm desatado em processos similares. É desta forma que resulta apropriada citar algumas palavras de Rickard Sandell, que informa o seguinte:

La situación demográfica cambiante por la que atraviesan casi todos los países árabes en este momento de su historia constituye una precondición específica para la región, que magnifica el efecto de los problemas económicos presentes en cada uno de los países árabes, y por consiguiente hace estallar con más facilidad el 
descontento latente en esta parte del mundo en este momento de su historia ${ }^{16}$

A transição demográfica de Egito, para um maior número de pessoas entre os 20 e 30 anos, apresenta um desafio para os administradores do Estado, pois a não ser assim, Sandell assinala que existiriam importantes disputas em dito território.

Tendo exposto as principais causas, deve ser dado passo ao conflito em si. Para isso analisaremos diversos artigos de imprensa que nos ajudam a compreender o episódio. Somado a isto, é necessário fazer uma comparação entre os jornais e canais informativos que se encontravam a favor do presidente e aqueles que analisavam de forma crítica os distúrbios, apegando-se à veracidade dos fatos.

O meio de comunicação "Global Voices", no dia terça-feira 25 de Janeiro de 2011 publicou o seguinte:

Los manifestantes salieron a las calles de El Cairo y muchas otras ciudades de Egipto el martes 25 de enero, que coincide con una fiesta nacional, "El Día de la Policía", para protestar contra el régimen autocrático de 30 años del Presidente Muhammad Hosni Mubarak...los manifestantes utilizaron redes sociales como Facebook y Twitter para coordinar sus acciones. En la noche, las redes

\footnotetext{
${ }^{16}$ SANDELL, Rickard, La "primavera árabe": ¿una primavera demográfica?, Cuadernos de pensamiento político $\mathrm{n}^{\circ} 33$. 2012, pág. 64
} 
de noticias hablaron de decenas de miles de egipcios acampando en la plaza principal de El Cairo, El-Tahrir, y las manifestaciones van a continuar el miércoles (...)Muchos observadores resaltaron la falta de cobertura de las protestas por las principales redes de noticias. La cobertura de Aljazeera fue particularmente escasa. Los periodistas ciudadanos han estado alimentando a los internautas con vídeos desde el interior de la manifestación ${ }^{17}$

A BBC mundo, no mesmo dia publicou:

Miles de personas se unieron a los disturbios tras una campaña convocada a través de las redes sociales, lo que llevó horas más tarde a las autoridades egipcias a bloquear el sitio de Twitter (...)En Washington, la Casa Blanca instó al presidente Hosni Mubarak a resolver esta crisis por medios no violentos. "El gobierno egipcio tiene una importante oportunidad de responder a las aspiraciones del pueblo egipcio y buscar reformas políticas, económicas y sociales que permitan mejorar sus vidas", aseguró en un comunicado" (...)Los inconformes marcharon por El Cairo y otras áreas coreando consignas contra el gobierno, luego de que algunos activistas pidieron un "Un día de revuelta" a través de un mensaje en Facebook. ${ }^{18}$

\footnotetext{
${ }^{17}$ Global Voices, Egipto: las protestas del 25 de enero en videos. ([em linha] Disponível em: http://es.globalvoicesonline.org/2011/01/26/egipto-las-protestas-del25-de-enero-en-videos/[2013, Setembro])

${ }^{18}$ Noticia BBC Mundo, 25 de enero de 2011. ([em linha] Disponível em: http://www.bbc.co.uk/mundo/noticias/2011/01/110125_egipto_cairo_revueltas_jrg.sht $\mathrm{ml}[2013$, Setembro])
} 
As notícias ilustram o gênesis dos 18 dias de protestos posteriores. Em esse dia a sociedade perdeu o medo do regime. No primeiro enunciado, adverte-se a importância da informação proporcionada pelos cidadãos, os vídeos, fotos etc. A diferença do segundo enunciado, em onde se dá uma análise com repercussões internacionais, ao incluir os comentários do governo Estadunidense. Em ambos os textos, se realça a importância das redes sociais de internet, as quais como se têm assinalado, têm sido fundamentais durante o processo.

Para o caso dos jornais egípcios, analisaremos dois em particular, o primeiro é Ao Ahram, um diário partidário do governo. O segundo é um diário privado, mas não de oposição, cujo nome é A oMasry A o-youm. A seguir ilustram-se alguns titulares do dia 26 de janeiro de 2011.

O meio Ao ahram expôs o seguinte:

El portavoz del Ministerio de Exteriores: las manifestaciones no son un nuevo fenómeno" (...) Algunos manifestantes tiran piedras a las fuerzas de seguridad que les intenta dispersar con mangueras de agua y bombas lacrimógenas. Intentos de atacar a la policía cuyo papel ha sido limitado a asegurar a los manifestantes que expresan libremente su opinión. Instrucciones del 
Ministro de Interior de no atacar a los manifestantes pacíficos. $^{19}$

No caso da o- Masry A o-youm, no mesmo dia publica-se:

Alarma: Miles de personas se manifiestan contra la pobreza, el paro, la subida de los precios y la corrupción, pidiendo la dimisión del gobierno (...)Al Baradey: La salida de los egipcios a las calles es el comienzo de un proceso histórico... la cultura del miedo se ha roto (...)Agredidos 6 periodistas de Al-Masry Al-Youm durante los acontecimientos. ${ }^{20}$

Como vemos, as diferenças estão à vista, já que, no caso de "Ao ahram", se tenta baixar o perfil às manifestações, enquanto no segundo meio cataloga-as como um fato histórico. De igual forma, "Ao ahram", enquadra-se com o labor policial, aludindo que têm resguardado aos manifestantes, ademais o meio realça as declarações dos órgãos do governo. A diferença do anterior, o diário privado, quantifica aos manifestantes, e assinala as principais causas pelas que se mobilizam, mostrando assim a relevância do descontentamento egípcio. Conjuntamente, assinala que existe feridos, algo não que se ignora no primeiro caso.

\footnotetext{
${ }^{19}$ Ídem.

${ }^{20}$ Ídem.
} 
Relatar a cronologia dos acontecimentos seria ambicioso, no entanto daremos um salto ao dia 11 de fevereiro de 2011, momento no qual se retira do poder Mubarak. Este fato foi uma notícia de alcances mundiais, é assim, por exemplo, que o diário "O Universo" de Equador relata o seguinte:

Hosni Mubarak deja la presidencia de Egipto". Luego desarrolla el titular; "El presidente egipcio, Hosni Mubarak, ha renunciado a su puesto, vencido al final por una ola histórica de 18 días de manifestaciones prodemocráticas en las que participaron cientos de miles de personas, y entregará el poder a las Fuerzas Armadas, anunció hoy el vicepresidente Omar Suleimán (...) El anuncio fue recibido con gritos de júbilo en la plaza de Tahrir, centro neurálgico de las protestas de las últimas semanas, mientras se escuchaban bocinazos y disparos al aire en la ciudad de 18 millones de habitantes. "El pueblo derrocó al presidente", coreaba la multitud frente al palacio presidencial. $^{21}$

Os egípcios desencadearam a derrocada de um governo, o saldo destas manifestações foi alto:

\footnotetext{
${ }^{21}$ Diario El universo, día 11 de febrero de 2011. ([em linha] Disponível em: http://www.eluniverso.com/2011/02/11/1/1361/hosni-mubarak-familia-dejancairo.html. [2013, Setembro])
} 
Al menos 840 personas fueron víctimas de homicidio o murieron en relación con las protestas, y más de 6.000 resultaron heridas. Miles de personas fueron recluidas y muchas sufrieron torturas o abusos ${ }^{22}$

Este é um dos lamentáveis custos de um processo revolucionário. Após a queda do presidente, foi o Conselho Supremo das Forças Armadas, quem assumiu o poder, com a promessa de celebrar em meados de 2012 eleições presidenciais. Efetivamente, no dia 24 de junho do ano de 2012, desenvolveram-se as eleições presidenciais, das quais resultou eleito Mohammed Mursi, membro do movimento Irmãos Muçulmanos, partido opositor a Mubarak e que tinha sido suprimido pelo ex-presidente. Contudo, vemos que existem desafios presentes para a sociedade egípcia, já que manter uma estabilidade democrática é uma tarefa árdua. Assim o reflete Khalidi na seguinte cita:

Las tareas más difíciles están aún por delante. No fue fácil derrocar a un tirano desconectado de la ciudadanía y a su codiciosa familia, ya sea en Túnez o en El Cairo. Construir un sistema democrático que funcione será mucho más arduo. Mucho más lo será aún que un sistema democrático, en caso de que pueda crearse, no quede dominado por los plutócratas que abundan en el mundo

${ }^{22}$ Fuente: Informe 2012 amnistía internacional. El estado de los derechos Humanos en el mundo. 
árabe ni por intereses poderosos y arraigados, como los militares. Por último, será una tarea de proporciones descomunales para cualquier nuevo régimen democrático popular alcanzar la justicia social y el rápido crecimiento económico necesario para proporcionar buenos trabajos, viviendas decentes, educación de calidad, las muy necesarias infraestructuras e igualdad de oportunidades. ${ }^{23}$

Finalmente, é necessário falar do futuro de Egito, sobretudo agora que se encontra em mãos de Mohammed Mursi, um islamista. Isso propõe duas arestas a analisar. A primeira diz relação com a secularização egípcia e em segundo lugar com o processo legal de um estado, isto é a criação de uma constituição. Quanto ao processo de secularização, no dia 30 de novembro de 2012, publicou-se uma notícia com o seguinte titular: "Comissão adota em Egito projeto de Constituição; a oposição manifesta-se" e em cujo desenvolvimento se propõe:

El proyecto señala que los "principios de la sharia" son "la fuente principal de la legislación", una formulación muy consensual en Egipto, que no convierte a los preceptos de la ley islámica en la única fuente del derecho. Eso sí, el proyecto añade una nueva disposición según la cual los principios de la "sharia" deben interpretarse según la doctrina sunita, una cláusula criticada por las iglesias cristianas y los opositores no islamistas. El proyecto de Carta Magna acuerda también al Estado un papel de

${ }^{23}$ KHALIDI, Rashid, Las revoluciones tunecina y egipcia, Revista Vanguardia Dossier no 39, Abril-Junio 2011. Pág.18 
"protección de la moralidad", y prohíbe "el insulto a las personas" y los "profetas", disposiciones que según algunos abrirán la puerta a la censura (...)La oposición liberal y laica, así como la iglesia copta, boicotearon los trabajos de la comisión, acusándola de dar la prioridad a las ideas de los islamistas(...)Se está dando "un golpe de Estado contra la democracia". "La legitimidad del régimen se está erosionando rápidamente ${ }^{24}$

$\mathrm{O}$ anterior deixa em manifesto a tendência islâmica do novo governo, e somada a isto, o descontentamento que isso provoca dentro da comunidade egípcia. Deve ser agregado que:

La precipitada adopción de este proyecto, que se había estancado durante meses, tuvo lugar en plena crisis política provocada por un decreto adoptado la semana pasada, por el cual Mursi se adjudicaba prerrogativas excepcionales, sobre todo respecto al poder judicial. ${ }^{25}$

Assim, vemos que a situação atual de Egípcio, também não é o mais auspicioso, como o aclara Fawaz A. Gerges, em seu artigo "O futuro de Egito", enunciando:

${ }^{24}$ Fuente: Radio Nederland, La emisora internacional holandesa. ([em linha] Disponível em: http://www.rnw.nl/espanol/bulletin/egipto-adopta-el-proyecto-deconstituci\%C3\%B3n-en-plena-crisis-pol\%C3\%ADtica. [2013, Setembro]) ${ }^{25}$ Ídem. 
La brecha entre lo laico y lo religioso constituye la fractura fundamental en la política egipcia, un foso que pone en peligro la transición del autoritarismo al pluralismo"26. De igual forma, Ignacio Álvarez-Ossorio, plantea "El hecho de que las revueltas no hayan abierto un proceso de secularización como muchos esperaban, sino que hayan allanado el camino para la conquista del poder por parte de los islamistas ha llevado a muchos a lanzar la voz de alarma por la supuesta existencia de una agenda oculta por parte de los movimientos islamistas. ${ }^{27}$

Esta situação vislumbrada por diferentes autores, ainda que no último caso, existe um grau de alarmismo, dará que falar durante as próximas semanas, mais ainda quando já ocorreram protestos na contramão da nova constituição egípcia. O futuro, deste problema histórico, está aberto às diferentes ações que tomem os cidadãos e o novo governo, no entanto uma coisa é certa, nos encontramos em frente a uma flor de primavera que está sendo açoitada por um inverno tormentoso.

${ }^{26}$ GERGES, F, El futuro de Egipto, La vanguardia articulos. 2011. ([em linha] Disponível em: http://www.lavanguardia.com/opinion/articulos/20111123/54239202290/fawazgerges-el-futuro-de-egipto-1.html. [2013, Setembro])

${ }^{27}$ ALVAREZ-OSSORIO, Igancio. Primavera democrática árabe: ¿otoño islamista? Ceipaz, Cambio de ciclo: crisis, resistencias y respuestas globales. Anuario 20122013. pág. 108 


\section{Reflexões finais}

"Ya hemos obtenido todo lo que queremos. Parece que el nuevo gobierno está bien. Tengo miedo de que estalle una guerra civil si las cosas empeoren". Anónimo. ${ }^{28}$

As raízes das manifestações egípcias são a aglomeração dos fatores trabalhados no desenvolvimento da investigação, pois de não ser assim, e ao analisar as causas por se sozinhas, tivéssemos tido acontecimentos similares em muitos outros países.

Os acontecimentos de Janeiro têm deixado à porta aberta a novas situações que ainda não têm sido reparadas na sociedade. A diferenciação entre religiões, e a chegada de um governo islamista, somado às necessidades de uma população jovem que se encontra ansiosa de um país mais igualitário e com maiores oportunidades, apresentam desafios enormes para Mohammed Mursi.

Existe uma alta percentagem da sociedade que está cansada e temerosa das novas circunstâncias na que se encontra a administração do país, sobretudo, quando se cria uma nova constituição. À medida que

\footnotetext{
${ }^{28}$ Fuente: Hosny, Yasmin, "Los discursos mediáticos nacionales de la revolución egipcia del 25 de enero y su repercusión en internet. Consideraciones discursivas e ideológicas". Universidad de El Cairo. Egipto. Revista electrónica de estudios filológicos. pág. 53
} 
se discutiu a nova carta magna, desenvolveram-se novos protestos, criando um ambiente delicado, que tem a muitas pessoas expectantes aos acontecimentos. Os custos, da revolução de princípios de 2011 foram centenas de vítimas, é por isso o receio dos cidadãos egípcios diante uma futura guerra civil.

A necessidade de estabilidade egípcia é transcendental para a região do Oriente Médio, pois o poderio militar e as alianças estratégicas são parte da história egípcia, é por isso que sua histórica liderança se encontra em dúvida:

Egipto se halla más habituado que el resto de países árabes a desempeñar el papel de líder. Sucede, sin embargo, que en esta ocasión hacer el papel de líder excede sus posibilidades económicas ${ }^{29}$

$\mathrm{O}$ anterior abre-nos possibilidades a novas investigações futuras, deixando em manifesto que hoje a situação egípcia não é a mais auspiciosa.

${ }^{29}$ ABURISH, Said. ¿liderazgo árabe? Revista de prensa "Tribuna libre". 2012. ([em linha] Disponível em: http://www.almendron.com/tribuna/liderazgo-arabe/. [2013, Setembro]) 


\section{Bibliografia}

ABURISH, Said. ¿liderazgo árabe? Revista de prensa "Tribuna libre". España, Marzo, 2012.

ALVAREZ-OSSORIO, Igancio. Primavera democrática árabe: ¿otoño islamista? Ceipaz, Cambio de ciclo: crisis, resistencias y respuestas globales. Anuario 2012-2013.

PIAZZA, Bárbara Azaola. Egipto ante la sucesión de Mubarak: oposición política y emergencia de nuevos actores, Documento de trabalho do Primeiro Congresso do Foro de Pesquisadores do Mundo Árabe e Muçulmano (FIMAM), Barcelona, 17-19 de março de 2004. Em site do FIMAM.

DE LAS HERAS, José Luis. Egipto: democracia de papel, Portal de egoverno, inclusão digital e sociedade do conhecimento. Santa Catarina, Brasil. Março 2011.

FERGANY, Nader. La "primavera de la reforma árabe" aún debe florecer, Med2006, editores IEMed.

GERGES, F, El futuro de Egipto, La vanguardia artículos. Barcelona, Noviembre, 2011.

HOBSBAWM, Eric. La era del capital 1848-1875, Editorial crítica, Buenos Aires. 2007

HOSNY, Yasmin, "Los discursos mediáticos nacionales de la revolución egipcia del 25 de enero y su repercusión en internet. Consideraciones discursivas e ideológicas". Universidad de El Cairo. Egipto. Revista electrónica de estudios filológicos.

ÍNDICE DE PERCEPCIÓN DE LA CORRUPCIÓN 2010. 
ÍNDICE DE PERCEPCIÓN DE LA CORRUPCIÓN 2011.

INFORME 2012 AMNISTÍA INTERNACIONAL. El estado de los derechos Humanos en el mundo

KHALIDI, Rashid, Las revoluciones tunecina y egipcia, Revista Vanguardia Dossier nº 39, Abril-Junio 2011.

KOROTAYEV Andrey, Egyptian revolution: a Demographic Structural Analysis, Revista Entelequia, sección Mundo contemporáneo. Primavera 2011.

MOSCOSO, Juan, Ante la primavera árabe, Revista Escritura pública $\mathrm{n}^{\circ} 69,2011$.

SANDELL, Rickard, La "primavera árabe": ¿una primavera demográfica?, Cuadernos de pensamiento político $\mathrm{n}^{\circ}$ 33. 2012.

\section{Referencias eletrônicas}

http://www.lavanguardia.com/internacional/20110401/54258834341/20 11-la-revuelta-arabe.html

http://www.rnw.nl/espanol/bulletin/egipto-adopta-el-proyecto-deconstituci\%C3\%B3n-en-plena-crisis-pol\%C3\%ADtica

http://www.almendron.com/tribuna/liderazgo-arabe/

http://www.radical.es/historico/informacion.php?iinfo=21367

http://www.lavanguardia.com/opinion/articulos/20111123/5423920229 0/fawaz-gerges-el-futuro-de-egipto-1.html 
Revista Vernáculo, $n^{o} 30,2^{\circ}$ sem/2012

http://actualidad.rt.com/themes/view/44199-Primavera\%C3\%81rabe?page $=9$

http://www.bbc.co.uk/mundo/noticias/2011/12/111229_primavera_arab e_hobsbawn_revolucion_pea.shtml?print $=1$

http://www.bbc.co.uk/mundo/noticias/2011/01/110125_egipto_cairo_re vueltas_jrg.shtml

http://www.letraslibres.com/revista/reportaje/egipto-el-largo-caminode-la-revolucion

http://blog.rtve.es/desdeisrael/2012/01/egipto-25-de-enero-larevoluci\%C3\%B3n-de-la-dignidad.html

http://www.letraslibres.com/revista/reportaje/egipto-el-largo-caminode-la-revolucion

http://www.um.es/tonosdigital/znum21/secciones/monotonosegipto.htm

http://es.globalvoicesonline.org/2011/01/26/egipto-las-protestas-del-25de-enero-en-videos/

http://www.revistadelibros.com/articulos/la-mujer-egipcia

http://www.rnw.nl/espanol/bulletin/egipto-adopta-el-proyecto-deconstituci\%C3\%B3n-en-plena-crisis-pol\%C3\%ADtica

http://es.globalvoicesonline.org/2011/01/26/egipto-las-protestas-del-25de-enero-en-videos/

http://www.alarabiya.net/articles/2011/01/25/134920.html. 
Revista Vernáculo, $n^{\circ} 30,2^{\circ}$ sem/2012

http://www.eluniverso.com/2011/02/11/1/1361/hosni-mubarak-familiadejan-cairo.htm 